\title{
O que fazer da pedra e cal? A experiência de ensino de políticas de cultura no Bacharelado em Gestão de Políticas Públicas da Universidade de São Paulo
}

\author{
André Fontan Köhler ${ }^{1}$
}

\author{
${ }^{1}$ Escola de Artes, Ciências e Humanidades da Universidade de São Paulo. \\ Correspondência: E-mail: afontan@usp.br \\ Av. Arlindo Béttio, 1000 \\ São Paulo - SP - Brasil \\ CEP 03828-000
}

Resumo O trabalho apresenta e discute a disciplina políticas de cultura do Bacharelado em Gestão de Políticas Públicas, em 2012, que versou sobre as políticas patrimoniais brasileiras. Cara a essa experiência de ensino é a noção de que, no campo da agenda governamental e políticas públicas, há um contraste entre a importância (conceitual e formal) e a falta de importância (real e efetiva) do patrimônio histórico e artístico nacional. Além disso, a temática não é devidamente abordada nos bacharelados de gestão e políticas públicas, nem conta com suficiente literatura analítica, histórica e de estudos de caso, no Brasil. O trabalho apresenta, como objetivo-fim, avaliar a disciplina, no que tange sua contribuição à formação de discentes de Gestão de Políticas Públicas e do Bacharelado em Lazer e Turismo. A metodologia de pesquisa consistiu em, além de revisar a experiência de lecionar a disciplina, entrevistar cinco discentes matriculados(as) - três aprovados(as) e dois(uas) reprovados(as). O artigo revela que a disciplina teve os seguintes méritos: a) a mescla de alunos(as) de Gestão de Políticas Públicas e Lazer e Turismo; b) a oportunidade de os(as) discentes descobrirem uma área até então ignorada no supracitado campo; e c) ter propiciado aos(às) discentes a reflexão sobre o conceito de nacional, travando contato com seu lado formativo e simbólico. Como pontos negativos, destacam-se os seguintes: a) a atuação profissional na área ainda não é avaliada como promissora e atrativa pelos(as) discentes; b) a disciplina careceu de maior contato com gestores(as) públicos(as) com atuação na área patrimonial, através de aulas e palestras; c) parte do corpo discente não teve o necessário empenho na disciplina; e d) a viagem técnica deveria ter contemplado, ao invés de Iguape, uma cidade patrimonial que melhor retrata os problemas comuns ao patrimônio cultural brasileiro.

Palavras-chave: patrimônio histórico e artístico nacional, políticas 
patrimoniais, Museu da Cidade de São Paulo, Iguape.

Abstract

Resumen
The paper presents and discusses the discipline cultural policies, of the Public Policies Management Undergraduate, in 2012, which was about the Brazilian heritage policies. Important to this educational experience is the notion that, in the field of governmental agenda and public policies, there is a contrast between the importance (conceptual and formal) and the lack of importance (real and effective) of the historic and artistic national heritage. Besides that, the issue is not properly addressed in public policies undergraduate courses, nor has sufficient analytic, historic and case studies literature in Brazil. The paper presents, as its main objective, to evaluate the discipline, regarding its contribution to the education of undergraduate students of Public Policy Management and Leisure and Tourism. The research methodology consisted of, besides reviewing the experience of teaching the discipline, interviewing five students enrolled - three approved and two disapproved. The article shows that the discipline has the following merits: a) the mixture between students of Public Policy Management and Leisure and Tourism; b) the opportunity for the students to discover an area hitherto ignored in the aforementioned field; and c) to have provided the students a reflection upon the concept of national, specifically with its identity and symbolic spheres. As negative points, we highlight the following: a) the work in the heritage area is not yet evaluated as promising and attractive by the students; b) there was a lack of contact with professionals and managers, through classes and lectures; c) some students did not have the necessary commitment to the discipline; and d) the technical travel should have contemplated, instead of Iguape, a heritage city that best portrays the innumerous problems faced by the Brazilian cultural heritage.

Keywords: historic and artistic national heritage, heritage policies, Museu da Cidade de São Paulo, Iguape.

El artículo presenta y discute la disciplina del curso cultura política de la Licenciatura en Gestión de Políticas Públicas en 2012, que se refería a las políticas de equidad de Brasil. Cara a esta experiencia educativa es la idea de que, en el ámbito de la política pública y la agenda gubernamental, hay un contraste entre la importancia (conceptual y formal) y la falta de importancia (real y eficaz) del patrimonio histórico y artístico. Por otra parte, el problema no se tratan correctamente en la licenciatura en administración y políticas públicas, ni tiene suficiente literatura analítica y estudios históricos de caso en Brasil. En el documento se presenta como objetivo final, la evaluación de la disciplina, en cuanto a su contribución a la formación de los estudiantes de las Políticas Públicas y Gestión del Curso de Licenciatura en Turismo y Ocio. La metodología de investigación consistió, además de examinar la experiencia de la enseñanza de la disciplina, entrevistando a cinco estudiantes matriculados (as) - tres aprobados (as) y dos (wo) desaprueba (as). El artículo revela que la disciplina tiene los siguientes méritos: a) la mezcla de alumnos (as) en Gestión y Políticas Públicas Ocio y Turismo b) oportunidad para el (los estudiantes) encontrar un área hasta ahora ignorado en dicha materia; y c) hayan facilitado a (la) a los estudiantes a reflexionar sobre el concepto de nacional, cerrando el contacto con su lado formativo y simbólico. Como puntos negativos, podemos destacar las siguientes: a) el desempeño profesional en el campo no se ha evaluado como prometedor y atractivo (a los estudiantes), b) carecían de disciplina administradores un mayor contacto con el (los) público (as) que actúa 
en la hoja, a través de cursos y conferencias, c) parte del alumnado no tenía el compromiso necesario para la disciplina, y d) la técnica debería haber contemplado viaje, en lugar de Iguape, un activo de la ciudad que mejor retrata los problemas comunes al patrimonio cultural Brasil.

Palabras-clave: patrimonio histórico y artístico, políticas patrimoniais, Museu da Cidade de São Paulo, Iguape. 


\section{Introdução}

Caro a todo Estado Moderno (Estado Nacional) é a constituição de um patrimônio histórico e artístico nacional (PHAN), que seleciona, atribui valor e delimita um conjunto de bens no espaço público. O PHAN cumpre três funções simbólicas básicas. Primeiro, esse patrimônio reforça a noção de cidadania, ao retirar parte dos direitos de propriedade de áreas, estruturas e objetos de indivíduos e firmas privadas, em favor do interesse público. Sendo assim, o Estado passa a ser coresponsável pelo conjunto de bens salvaguardados, para o desfrute e a instrução dos cidadãos. Segundo, o PHAN “materializa” a entidade ideal que é a nação, demarcando-a no tempo e no espaço - segundo Guizot, criador do cargo de inspetor dos monumentos históricos franceses, em 1830, o solo francês era representado por seus monumentos. Terceiro, os bens patrimoniais documentam e "comprovam" a versão oficial da história nacional; trata-se de provas materiais que confirmam seus mitos de origem e o direito de ocupação do território (Fonseca 2005, Choay 2006).

Weffort (2004) deixa claro que o Estado Moderno surge no Brasil apenas nos anos 1930, já que o Estado da República Velha (1889-1930) era de tipo oligárquico e patrimonialista. Não por acaso, a principal peça de legislação, que conceitua e organiza a proteção do PHAN pelo Estado brasileiro, ainda é o Decreto-lei n. 25, de 30 de novembro de 1937, publicado no início do Estado Novo (1937-1945) (Brasil 1937).

A criação do Bacharelado em Gestão de Políticas Públicas (GPP), em 2005, na Escola de Artes, Ciências e Humanidades da Universidade de São Paulo (EACH/USP), proporcionou a retomada do campo da gestão governamental e políticas públicas na maior e mais importante instituição de ensino superior brasileira; a Faculdade de Economia, Administração e Contabilidade da Universidade de São Paulo ofertou o Bacharelado em Administração Pública, entre 1965 e 1973, inclusive (Graduação em Gestão de Políticas Públicas 2012). Dentro da proposta de ser um curso inovador e interdisciplinar, baseado na Administração, Ciências Sociais, Economia e Direito, GPP contemplou, desde sua primeira grade curricular, a disciplina Políticas de Cultura (ACH3598), sem, entretanto, contratar ou vincular um(a) docente particular a ela.

Isso fez que com a supracitada disciplina, nos últimos anos, tenha sido ofertada por professores(as) com formações acadêmicas e campos de interesses distintos, fazendo com que ela "adotasse" temas tão diferentes entre si quanto as políticas patrimoniais e a questão dos direitos autorais, no Brasil e no mundo.

O objeto de estudo desse trabalho é a disciplina Políticas de Cultura (ACH3598), mais especificamente sua oferta no primeiro semestre de 2012, quando versou sobre as políticas patrimoniais brasileiras. Cabe, dessa forma, abordar seu tema e conteúdo, a organização de aulas e atividades extraclasses e os(as) discentes matriculados - procedência, motivações, desempenho e avaliação da disciplina. Em suma, trata-se de fazer um balanço geral da disciplina, que versou sobre uma 
política setorial pouco contemplada em cursos de bacharelado de administração pública e políticas públicas, e que conta com uma literatura analítica, histórica e de estudos de caso escassa, principalmente para o caso brasileiro.

Tem-se como objetivo-fim a avaliação da supracitada disciplina, no primeiro semestre de 2012, no que tange sua contribuição à formação de discentes de GPP e do Bacharelado em Lazer e Turismo (LZT). Essa contribuição pode ser medida através de quatro pontos principais, a saber: a) compreensão da legitimidade e pertinência da intervenção do Estado brasileiro na área patrimonial; b) compreensão da importância do PHAN para a formação e consolidação da cidadania brasileira; c) análise e avaliação das relações possíveis e desejáveis entre o PHAN e o lazer, turismo e entretenimento; e d) contextualização e avaliação da trajetória das políticas patrimoniais brasileiras, travando contato com seus principais problemas, desafios e oportunidades.

Basicamente, há duas justificativas para esse trabalho. Primeiro, as políticas patrimoniais - pode-se dizer o mesmo até do conjunto das políticas culturais não são avaliadas como pertencentes ao grupo das principais funções e políticas setoriais de Estado. No Brasil, não é incomum docentes, especialistas e discentes do campo da gestão governamental e políticas públicas considerarem as políticas patrimoniais supérfluas e sem sentido; o próprio tema parece, para alguns, fazer parte da arquitetura e urbanismo, e não da gestão pública. Não é raro encontrar graduandos(as) de GPP, no quarto ou quinto ano do curso, que não fazem ideia de o que é tombamento, ou mesmo que exista o Instituto do Patrimônio Histórico e Artístico Nacional (IPHAN), quando a autarquia completou, em 2012, setenta e cinco anos de existência.

llustrativo dessa realidade é o relato de um discente de GPP, no quinto ano do curso, ao conversar com o docente responsável sobre a possibilidade de cursar Políticas de Cultura:

Foi legal cursar teoria dos jogos com o senhor I professor responsável por Políticas de Cultura], mas eu não vejo sentido em cursar essa matéria; ficar estudando prédio velho, igreja velha, para que? ... Eu acho que isso tem mais a ver com arquitetura; qual é a responsabilidade do Estado em cuidar desse patrimônio? Talvez [seja pertinente] em algumas cidades, como Ouro Preto e Olinda. Agora, em São Paulo? Não sobrou nada mesmo. (Diálogo na cidade de São Paulo, 05 de fevereiro de 2012).

Segundo, o PHAN vem passando por avançado processo de deterioração, com perdas mensais de elementos e mesmo de edificações inteiras. A falta de recursos, tanto na recuperação de conjuntos e monumentos degradados quanto na preservação de bens tombados, o desuso do patrimônio protegido e a pouca 
atratividade desse tipo de bem cultural fizeram com que, em meados dos anos 1990, segundo dados do próprio IPHAN, cerca de 50\% dos imóveis históricos sob tutela federal se encontrassem degradados, e 25\% necessitassem de obras de recuperação. Essa mesma pesquisa indicou, ainda, que aproximadamente dois terços desses imóveis encontravam-se abandonados ou subutilizados (Taddei 1998). Ainda de acordo com essa fonte, seria necessário, à época, o equivalente a US\$ 1 bilhão para a recuperação integral do acervo então tombado, bem como o dispêndio de US\$50 milhões anuais para sua conservação.

A metodologia de pesquisa consistiu em, além de revisar a própria experiência de lecionar a Políticas de Cultura (ACH3598), no primeiro semestre de 2012, entrevistar cinco discentes matriculados(as) nessa disciplina - três aprovados(as) e dois(uas) reprovados(as) -, para enriquecer a visão dos(as) alunos(as) sobre a matéria, além de mais bem avaliar as oportunidades, limites e pontos positivos e negativos da disciplina.

\section{O Bacharelado em Gestão de Políticas Públicas: Importância, lógica geral e o papel de políticas de cultura}

A criação da EACH, em 2005, não representou apenas a oferta de dez novos cursos de graduação na Universidade de São Paulo (USP), com um total de $\mathbf{1 . 0 8 0}$ vagas anuais. Ela também representou uma tentativa de modernizar e inovar a universidade, no que tange sua organização interna, o ensino e formação do corpo discente e a oferta de cursos com lógicas e campos de atuação distintos dos já existentes em outras unidades da USP.

No tocante aos dez cursos criados - entre eles GPP e LZT -, implantaram-se propostas inovadoras, a partir de óticas multidisciplinares e interdisciplinares e ramos de atuação emergentes, ou, então, que enfrentavam severa escassez de profissionais no mercado (por exemplo, no caso do Bacharelado em Obstetrícia).

A criação de GPP representou um marco no processo de (re)valorização do ensino de graduação no campo da gestão governamental e políticas públicas, nos últimos anos, que reflete o fortalecimento do papel do Estado, através do movimento de reforma do Estado, a partir dos anos 1990, a consolidação da democracia, tendo como marco a Constituição da República Federativa do Brasil, de 1988, e a ampliação do conceito de público, que, hoje, contempla as organizações não governamentais e os movimentos sociais (Graduação em Gestão de Políticas Públicas 2012).

Tendo como pilares a Administração, Ciências Sociais, Economia e Direito, como colocado anteriormente, a grade curricular de GPP privilegia uma formação generalista; as disciplinas que versam sobre temas específicos e políticas setoriais são todas optativas livres; ou seja, fica a critério de cada discente 
escolher como cumprir trinta e seis créditos de optativas, dentro do conjunto de disciplinas ofertadas semestral e anualmente pela USP. ISSO permite ao(à) discente aprofundar-se em temas e políticas setoriais de seu interesse, recorrendo inclusive a outras unidades da universidade.

GPP oferta vinte e sete disciplinas optativas centradas em temas específicos e políticas setoriais, dentre elas Temas de Políticas Públicas (I e \|I), Temas de Gestão Pública (I, II e III) e Seminários de Políticas Públicas Setoriais (I ao VIII), além das seguintes: a) Políticas Públicas de Saúde (ACH3557); b) Políticas Públicas para Educação no Brasil (ACH3567); c) Políticas Públicas de Trabalho e Emprego (ACH3577); d) Política Agrícola e de Reforma Agrária (ACH3587); e) Política Industrial (ACH3597); f) Política Urbana e Regional (ACH3558); g) Gestão de Políticas Públicas em Cooperativismo Social (ACH3568); h) Políticas Públicas para Inclusão Social (ACH3578); i) Políticas de Segurança (ACH3588); e j) Políticas de Cultura (ACH3598).

A disciplina Políticas de Cultura (ACH3598) já fazia parte da primeira grade curricular de GPP; desde 2006, é uma optativa livre, apesar de não ter sido ofertada todos os anos. Seu tema e conteúdo mudam ano a ano, a depender do(a) docente responsável. Como visto anteriormente, além de políticas patrimoniais, a disciplina já contemplou propostas ligadas à questão dos direitos autorais no Brasil e no Mundo.

Políticas de cultura contemplou as políticas patrimoniais - ou a questão dos bens culturais no Brasil, como diria Aloísio Magalhães - em duas oportunidades, em 2008 e 2012. É sobre essa segunda experiência que o trabalho debruça-se, a partir de agora.

Por que contemplar as políticas patrimoniais em Políticas de Cultura (ACH3598)? A importância e falta de importância da área patrimonial na agenda governamental e no campo da gestão de políticas públicas

Os dois primeiros parágrafos da Introdução já deixaram clara a importância da constituição do PHAN no Brasil. Além disso, desde pelo menos 1937, o Estado brasileiro exerce tutela sobre o acervo tombado, na forma de monumentos isolados, conjuntos arquitetônicos e paisagísticos, acervos e paisagens culturais, entre outros. O decreto-lei 25, de 30 de novembro de 1937, estabelece a responsabilidade de o Estado salvaguardar o patrimônio cultural brasileiro, em seu artigo primeiro: 
Art. 1․ Constitui o patrimônio histórico e artístico nacional o conjunto dos bens móveis e imóveis existentes no país e cuja conservação seja de interesse público [grifo nosso], quer por sua vinculação a fatos memoráveis da história do Brasil, quer por seu excepcional valor arqueológico ou etnográfico, bibliográfico ou artístico. (Brasil 1937:1).

A responsabilidade do Estado com a salvaguarda do patrimônio cultural foi reforçada pela Constituição da República Federativa do Brasil, de 1988, que, além disso, ampliou seu conceito, abrindo caminho para a institucionalização do patrimônio imaterial - manifestações folclóricas, lugares sagrados, artes, técnicas e ofícios, festas, etc. - e o progressivo reconhecimento do legado dos vários grupos sociais formadores da sociedade brasileira. O artigo 216 da constituição federal deixa clara a tentativa de alargar e "pluralizar" o PHAN, bem como o compromisso do Estado com sua salvaguarda:

Art. 216. Constituem patrimônio cultural brasileiro os bens de natureza material e imaterial, tomados individualmente ou em conjunto, portadores de referência à identidade, à ação, à memória dos diferentes grupos formadores da sociedade brasileira, nos quais se incluem: I - as formas de expressão; /l - os modos de criar, fazer e viver; /ll - as criações científicas, artísticas e tecnológicas; IV - as obras, objetos, documentos, edificações e demais espaços destinados às manifestações artístico-culturais; $V$ - os conjuntos urbanos e sítios de valor histórico, paisagístico, artístico, arqueológico, paleontológico, ecológico e científico. (Brasil 1988:111).

Contudo, a importância da constituição do PHAN no Brasil e a responsabilidade legal do Estado sobre o acervo salvaguardado não têm sido suficientes para seu reconhecimento perante a sociedade, nem para justificar uma ação pública mais estruturada e relevante na área patrimonial, nas três esferas de governo. Há, aqui, três pontos a destacar. Primeiro, há sérios problemas de recepção do PHAN no país. Grande parte da população nele não se reconhece, nem o valoriza, tampouco consegue compreender qual é sua utilidade, a ponto de justificar a intervenção pública em serviços de preservação, utilização e valorização desse patrimônio cultural.

Fonseca (2005) aponta que, de modo geral, a população foi vista como "massa" pelo IPHAN, durante a fase heroica (1937-1967), pois era considerada incapaz de compreender o valor e sentido do PHAN. Nota-se a ausência de ações de educação patrimonial, inclusive através do ensino público formal, mesmo o IPHAN tendo permanecido por quase cinquenta anos no Ministério da Educação e Saúde Pública, depois Ministério da Educação e Cultura (MEC). Além disso, há 
uma diferença muito grande nos critérios de valorização dos bens tombados; enquanto a autarquia federal de preservação sempre privilegiou o valor artístico (estético) em detrimento do valor histórico, a população, de modo geral, valoriza mais a antiguidade, beleza e riqueza desses bens.

Isso faz com que o PHAN seja pesado e mudo, pesado porque mudo:

Valioso, trata-se, porém, de um patrimônio pesado e mudo. Pesado, não só por sua monumentalidade, pela solidez dos materiais e pelo lugar que ocupa no espaço público. Pesado porque mudo, na medida em que, ao funcionar apenas como símbolo abstrato e distante da nacionalidade I grifo nossol, em que um grupo muito reduzido se reconhece, e referido a valores estranhos ao imaginário da grande maioria da população brasileira, o ônus de sua proteção e conservação acaba sendo considerado como um fardo por mentes mais pragmáticas. (Fonseca 2005:26-27).

Indicativo disso é a discussão, ainda hoje presente nos meios intelectuais e acadêmicos, de que o Brasil tem população, não povo; Szmrecsányi (2011), por exemplo, defende que, ao ter adiado ao conjunto da população brasileira os direitos básicos de cidadania, o processo de formação de um povo brasileiro ainda está incompleto, o que faz com que a noção de patrimônio cultural não consiga ganhar força e reconhecimento no país.

Já Ortiz (2006) mostra como as questões levantadas por parte dos intelectuais do Instituto Superior de Estudos Brasileiros (ISEB) são fundamentais para se compreender as discussões sobre cultura brasileira e identidade nacional presentes na sociedade como um todo, que adentraram os anos 1960 , chegando ao século XXI. O autor aponta que termos como cultura alienada, colonialismo e autenticidade cultural, forjados pelo ISEB, no final dos anos 1950, transformaramse, nas décadas seguintes, em categorias de apreensão e compreensão da realidade nacional, sendo utilizados até com certa "naturalidade." Cara a esses intelectuais era a noção de que o povo brasileiro ainda estava em formação, e precisava tomar consciência de sua situação para superar a situação colonial na qual o país encontrava-se.

Segundo, o PHAN tem sido alvo de políticas públicas que, sem desprezarem a esfera propriamente cultural - simbólica por excelência -, têm como principais objetivos a recuperação de áreas centrais deterioradas de grandes cidades, o desenvolvimento econômico local e a promoção do lazer, turismo e entretenimento. Nos anos 1970, o Programa Integrado de Reconstrução das Cidades Históricas do Nordeste, com sua utilização para fins turísticos (PCH), foi pioneiro; resultado de uma proposta conjunta da Secretaria de Planejamento da Presidência da República (SEPLAN/PR) e do MEC, o programa avaliava que as 
cidades históricas da região Nordeste possuíam um vasto e rico acervo histórico, artístico e cultural, que se encontrava sem uso e em estado de conservação insatisfatório (Brasil 1973).

Desvinculado da orientação museológica do IPHAN, o PCH tinha como principal objetivo o desenvolvimento econômico e social de localidades pobres da região Nordeste, que, de forma geral, tinham grande parte de seu patrimônio cultural preservado em função da estagnação econômica pela qual tinham passado. Ao invés de recuperar esse patrimônio levando-se em conta apenas o valor histórico e artístico dos monumentos e conjuntos arquitetônicos e paisagísticos tombados, - programa considerava seu potencial turístico, tratando os bens culturais como instrumentos de geração de emprego e renda na comunidade (Miceli 1984).

Tomando como exemplo um caso mais recente, o Programa Monumenta, desde 2010 administrado pelo IPHAN, contempla a recuperação de monumentos e conjuntos arquitetônicos e paisagísticos dentro de estratégias de desenvolvimento econômico local, que incluem a consideração da sustentabilidade econômico-financeiro do patrimônio cultural recuperado. No período 2008-2011, respondeu, sozinho, por 31,2\% do investimento em programas finalísticos - R\$ $152.296 .000,00$ do total de $R \$ 488.324 .000,00-$, atrás apenas do Brasil Patrimônio Cultural/IPHAN, programa carro-chefe da autarquia federal (Brasil 2012).

Terceiro, apesar de o Ministério da Cultura e IPHAN terem conseguido expressivo aumento de recursos humanos e financeiros, desde 2003 - por exemplo, o orçamento total da autarquia federal passou de $\mathbb{R} \$ 101.668 .000,00$, em 2003, para $R \$ 228.084 .000,00$, em 2011 (Brasil 2012) -, a área patrimonial ainda não ocupa um espaço importante na agenda governamental e no campo de gestão de políticas públicas. Um caso ilustrativo disso é o desconhecimento, por parte de discentes de GPP, da própria responsabilidade do Estado sobre os bens culturais tombados, como visto anteriormente.

Em resumo, a disciplina Políticas de Cultura (ACH3598), no primeiro semestre de 2012, centrou-se nas políticas patrimoniais, em virtude desse contraste entre a importância (conceitual e formal) e a falta de importância (real e efetiva) do PHAN no Brasil.

Coube, desse modo, não ter ofertado essa disciplina dentro de uma estratégia de convencimento forçado da importância do PHAN, nem de ocultação dos sérios problemas das políticas patrimoniais brasileiras, dos anos 1930 ao século XXI, tampouco de desconsideração da arbitrariedade e parcialidade existentes na construção dos mitos de origem, do patrimônio cultural e da identidade de qualquer nação, inclusive do Brasil. Cumpriu-se, isso sim, ter introduzido o corpo discente de GPP e LZT na questão dos bens culturais do Brasil, dando-lhe oportunidade de travar contato com a área patrimonial, compreender a trajetória dessas políticas públicas, e discutir as oportunidades, ameaças e pontos positivos e negativos desse campo no Brasil. 


\section{A organização da disciplina Políticas de Cultura (ACH3598):} introdução ao estudo das políticas patrimoniais brasileiras e imersão na questão dos bens culturais (Iguape e Museu da Cidade de São Paulo)

O semestre letivo foi composto, basicamente, por três tipos de atividade, a saber: a) aulas expositivas, com tempo para dúvidas e discussão, no final de cada aula; b) visita técnica a cinco unidades do Museu da Cidade de São Paulo (MCSP); e c) viagem técnica à Cidade de Iguape, Estado de São Paulo.

Dentro do caráter introdutório da disciplina, as aulas expositivas centraram-se no básico para a compreensão das políticas patrimoniais, inclusive pelo pouco tempo disponível; da carga horária total de trinta horas semestrais, apenas catorze delas prestaram-se às aulas expositivas, dado a necessidade de aplicação de prova parcial e exame, além das atividades extraclasse, já citadas.

Dado o público misto da disciplina - GPP e LZT -, passou-se, logo no início do semestre, dois textos básicos ao corpo discente. Souza (2006) traz uma ampla revisão sobre o campo de políticas públicas, desde seus principais conceitos até a análise do papel das instituições e das regras no processo de decisão e formulação de políticas públicas. Já Köhler e Durand (2007) proporcionam que o discente de GPP trave contato com o campo do turismo, com ênfase no turismo cultural, a partir de extensa revisão de literatura analítica e de estudos de caso.

Nas duas primeiras aulas, optou-se por apresentar e discutir conceitos básicos ao estudo das políticas patrimoniais - cultura, patrimônio, identidade e memória. No primeiro caso, utilizou-se Botelho (2001), Bennett (1995) e Volkerling (1996) para tal; o primeiro texto é particularmente útil para mostrar aos(às) alunos(as) duas concepções básicas de cultura, que geram políticas culturais bastante diferentes entre si.

Botelho (2001) explora duas dimensões para trabalhar com o conceito de cultura. Na dimensão antropológica, considera-se que todo e qualquer indivíduo é tanto produtor quanto consumidor de cultura, cultura essa presente nas relações sociais que a pessoa estabelece com a realidade a sua volta, ou seja, em seu cotidiano. Nesse sentido, a cultura refere-se ao trabalho, utilização do tempo livre, relações familiares, de amizade e vizinhança, hábitos, costumes e crenças em suma, tudo o que o indivíduo produz e consome material e simbolicamente em seu dia-a-dia. Como bem resume Botelho (2001:74): "Na dimensão antropológica, a cultura se produz através da interação social dos indivíduos, que elaboram seus modos de pensar e sentir, constroem seus valores, manejam suas identidades e diferenças e estabelecem suas rotinas." 
Na dimensão sociológica, a cultura assume o sentido da produção artística em sentido estrito, ou seja, trata-se de uma produção cultural que busca construir um determinado conjunto de sentidos, através de técnicas artísticas particulares, sendo direcionada também a um público-alvo. Sendo assim, a dimensão sociológica implica a criação e circulação de cultura em um "circuito organizacional que estimula, por diversos meios, a produção, a circulação e o consumo de bens simbólicos, ou seja, aquilo que o senso comum entende por cultura" (Botelho 2001:74). Têm-se aqui a prática profissional e as atividades amadoras.

O conceito de patrimônio cultura/ baseou-se em Fonseca (2005) e Choay (2006), assim como os de identidade e memória. Fonseca (2005:21) é quem mais bem sintetiza no que consiste as políticas patrimoniais:

A constituição de patrimônios históricos e artísticos nacionais é uma prática característica dos Estados modernos que, através de determinados agentes, recrutados entre os intelectuais, e com base em instrumentos jurídicos específicos, delimitam um conjunto de bens no espaço público. pelo valor que Ihes é atribuído, enquanto manifestações culturais e enquanto símbolos da nação, esses bens passam a ser merecedores de proteção, visando à sua transmissão para as gerações futuras. Nesse sentido, as políticas de preservação se propõem a atuar, basicamente, no nível simbólico, tendo como objetivo reforçar uma identidade coletiva, a educação e a formação de cidadãos. Esse é, pelo menos, o discurso que costuma justificar a constituição desses patrimônios e o desenvolvimento de políticas públicas de preservação.

Antes de entrar no caso brasileiro, mais dois tópicos foram contemplados pelas aulas expositivas. Primeiro, utilizou-se Volkerling (1996) para apresentar e discutir a trajetória das políticas culturais, no período 1945-1995, na Europa Ocidental e Estados Unidos da América, mostrando como suas lógicas, objetos e campos de intervenção e objetivos sofreram profundas mudanças, ao longo desses cinquenta anos.

Segundo, discutiram-se as principais cartas patrimoniais, documentos que estabelecem normas e conceitos relativos ao patrimônio cultural, desde a Carta de Atenas, de 1931, que expõe princípios gerais e doutrinas relativos à proteção de monumentos, até a Convenção para a salvaguarda do patrimônio cultural imaterial, de 2003, publicada pela Conferência Geral da Organização das Nações Unidas para a Educação, a Ciência e a Cultura. Apesar de todas elas estarem disponíveis em formato digital, Cury (2004) organiza-as, trazendo um índice remissivo útil à pesquisa de temas específicos. Para efeito da disciplina, as principais são as seguintes: a) Carta de Atenas (Sociedade das Nações 1931); b) 
Carta de Atenas (Congresso Internacional de Arquitetura Moderna 1933); c) Carta de Veneza (Conselho Internacional dos Monumentos e Sítios 1964); d) Normas de Quito (Organização dos Estados Americanos 1967); e) Compromisso de Brasília (1970); f) Compromisso de Salvador (1971); g) Convenção sobre a Salvaguarda do Patrimônio Mundial, Cultural e Natural (Conferência Geral da Organização das Nações Unidas para a Educação, a Ciência e a Cultura 1972); e h) Convenção para a Salvaguarda do Patrimônio Cultural Imaterial (Conferência Geral da Organização das Nações Unidas para a Educação, a Ciência e a Cultura 2003).

A descrição, análise e avaliação das políticas patrimoniais brasileiras ocuparam a maior parte das aulas expositivas. Inicialmente, foram apresentados os antecedentes dessas políticas - considera-se como sua data inaugural a publicação do decreto-lei 25, de 30 de novembro de 1937. Mostrou-se como a ação governamental era irrelevante e fragmentada na área patrimonial, na República Velha (1889-1930).

No início do século XX, não havia um órgão voltado à salvaguarda do PHAN no Brasil (Costa 1986). A antiga Inspetoria de Monumentos, surgida na República Velha, funcionava precariamente, com alcance praticamente restrito aos monumentos e museus da cidade do Rio de Janeiro, então capital federal. Protegendo bens esparsos sem uma legislação específica, com um reduzido corpo técnico e carência crônica de recursos, a inspetoria resumia a atuação do governo federal na área cultural. Além, é claro, da manutenção de alguns museus, como, por exemplo, o da Quinta da Boa Vista, e de instituições, como, por exemplo, a Biblioteca Nacional e a Escola Nacional de Belas Artes.

Além disso, a função social da propriedade, que restringe os direitos da propriedade privada, só foi reconhecida pela Constituição da República dos Estados Unidos do Brasil, promulgada em 1934, ponto de fundamental importância para a instituição do tombamento, em 1937, pois evitava a necessidade de o Estado desapropriar um bem cultural para preservá-lo (Brasil 1934).

Após os antecedentes, a disciplina centrou-se na criação e atuação do IPHAN durante a fase heroica (1937-1967), dentro do contexto de formação do Estado Moderno no Brasil, no primeiro período Vargas (1930-1945). Destaca-se, entre o amplo conteúdo dado, um ponto interessante da formulação do conceito de PHAN, consolidado na direção do IPHAN por Rodrigo Melo Franco de Andrade por trinta anos ininterruptos (1937-1967) e na escolha, por parte dele, de seu sucessor, Renato Soeiro (1967-1979).

Ao se rotular a arquitetura colonial como histórica e inscrita no passado, criou-se uma forte justificativa para sua recuperação e preservação. No caso específico do IPHAN, o patrimônio cultural a ser recuperado e preservado pela autarquia consistia nos bens móveis e imóveis considerados de valor histórico ou de grande valor arquitetônico e/ou escultórico, os chamados monumentos de pedra e cal do Brasil Colônia (Magalhães 1997). Isso levou a uma valorização, mais que de um 
estilo de arquitetura, de todo o acervo de objetos domésticos ou de trabalho, sacros ou leigos, de núcleos coloniais brasileiros, como Ouro Preto, pertencente aos séculos XVI, XVII e XVIII. No limite, isso acabou gerando um fluxo de procura por objetos de época e a transferência de muitos deles para coleções privadas nacionais e internacionais (Durand 1989).

Isso fez com que o PHAN tornasse-se um retrato em pedra e cal, segundo Fonseca (2005), ou, então, consistisse dos monumentos de pedra e cal representativos da etnia branca e de sua elite militar, eclesiástica e civil, seguindo-se Falcão (1997), com a marginalização das manifestações populares, do legado das etnias negra e indígena e de estilos arquitetônicos como o ecletismo. Junto com a falta de ações de educação patrimonial e a visão da população como "massa," não é difícil de entender o porquê de o patrimônio cultural brasileiro ser pesado e mudo, pesado porque mudo, como visto anteriormente.

Após a fase heroica, a disciplina contemplou as políticas patrimoniais durante o regime militar (1964-1985), com destaque para suas três propostas de renovação, a saber: a) a proposta "interna," ou seja, com origem no próprio IPHAN, que buscou renovar a atuação da autarquia através de uma parceria com a Organização das Nações Unidas para a Educação, a Ciência e a Cultura, a partir da experiência francesa de reabilitação de conjuntos arquitetônicos e paisagísticos; b) a proposta do $\mathrm{PCH}$, já vista nesse trabalho, surgida na SEPLAN/PR; e c) a proposta do Centro Nacional de Referência Cultural (CNRC), com destaque para a atuação de Aloísio Magalhães, que pretendia ampliar e renovar o conceito de PHAN e a atuação governamental na área patrimonial, inclusive recuperando pontos do famoso anteprojeto de lei de Mário de Andrade, dos anos 1930. Magalhães (1997) foi o texto base para a descrição, análise e avaliação da criação e atuação do CNRC; além dos textos já citados, o PCH contou com Instituto do Patrimônio Histórico e Artístico Nacional (1973), que também foi usado para a abordagem da proposta "interna".

Após consideráveis avanços conceituais, organizacionais e orçamentários, nos anos 1970, é interessante notar como a área patrimonial retrocedeu na agenda governamental e no campo de políticas públicas, principalmente com o início do processo de redemocratização, nos anos 1980. A questão do PHAN foi relegada ao segundo plano das políticas públicas de cultura, mesmo com a ascensão de Aloísio Magalhães à Secretaria de Cultura do MEC. Como prenuncia Machado (1984:13):

De qualquer maneira, com a permanência do processo de abertura, tenho para mim que uma política cultural centrada no conceito de patrimônio histórico tenderia a esgotar-se rapidamente. É que a clientela da outra vertente, a da criação do bem cultural (cinema, teatro, música popular, etc.), é muito mais dinâmica, organizada e politicamente ativa, razão pela 
qual suas demandas terão maior peso no processo de decisão sobre a alocação de recursos das agências que atuam na área cultural.

Nas últimas aulas expositivas, outros cinco pontos foram abordados em Políticas de Cultura; infelizmente, dada a falta de tempo, não houve o aprofundamento necessário em nenhum deles, mas se indicou aos(às) discentes textos complementares ao conteúdo dado em sala de aula. O primeiro ponto foi o alargamento e pluralização do conceito de PHAN no Brasil, nas últimas décadas, com destaque para o papel da Constituição da República Federativa do Brasil, de 1988, e do Decreto 3.551, de 04 de agosto de 2000, que instituiu o Registro de Bens Culturais de Natureza Imaterial e o Programa Nacional do Patrimônio Imaterial (Brasil 2000). Comentou-se também sobre vários projetos de unidades da federação e municípios, que identificam e valorizam seu patrimônio imaterial, a exemplo do Registro do Patrimônio Vivo, do governo estadual de Pernambuco, que reconhece e remunera indivíduos com relevantes serviços prestados à cultura pernambucana.

O segundo ponto foi a criação do Programa Monumenta, cuja ideia inicial é de 1995, hoje incorporado ao IPHAN. Contando com financiamento parcial do Banco Interamericano de Desenvolvimento, o programa tem como objetivo a recuperação de sítios e prédios históricos, a partir de uma filosofia que tem como pontos principais a sustentabilidade, visibilidade, atratividade e acessibilidade do patrimônio cultural (Gastal 2003). Infelizmente, o docente responsável, no primeiro semestre de 2012, ainda não estava a par dos mais recentes desenvolvimentos desse programa, o que impediu uma análise e avaliação mais profunda e completa do mesmo.

O terceiro ponto foram as leis de incentivo fiscal. Apesar do grande interesse do corpo discente em sua discussão, notadamente o caso da Lei Rouanet, cabe destacar que essas leis foram e são mais importantes para outras áreas culturais, a exemplo do teatro e audiovisual, do que para a área patrimonial.

Os dois últimos pontos foram discutidos brevemente em sala de aula; indicou-se, para os(as) discentes interessados(as), a leitura de textos complementares, bem como a disponibilidade de procurar o docente responsável fora da sala de aula, para eventuais dúvidas e esclarecimentos. O quarto ponto consistiu em explorar as relações existentes e possíveis entre o patrimônio cultural e o planejamento urbano e regional, utilizando-se Harvey (2005) como texto básico. O quinto ponto explorou as relações existentes e possíveis entre o patrimônio cultural e o lazer, turismo e entretenimento, a partir de Köhler (2011) e Meethan (1996).

A visita técnica contemplou cinco unidades do MCSP, a saber: a) casa do Sítio da Ressaca; b) Casa Modernista; c) Beco do Pinto; d) Solar da Marquesa de Santos; e e) Casa da Imagem. O patrimônio cultural de Minas Gerais foi elevado à condição de nacional, secundado pelos acervos do Rio de Janeiro, Bahia e Pernambuco, 
principalmente, ao passo que o patrimônio cultural do Estado de São Paulo foi considerado, antes de tudo, paulista, cuja importância e relevância eram essencialmente estaduais; isso motivou a visita técnica ao MCSP - ver como o patrimônio cultural da metrópole nacional primária era tratado pelo governo local.

Além disso, a cidade de São Paulo tem passado por profundas transformações, desde o último quartel do Século XIX, que alteraram radicalmente sua fisionomia urbana; Toledo (2007) utiliza o sugestivo subtítulo três cidades em um século, para reforçar a ideia de que São Paulo é uma cidade que se devora; a colonial devorada pelos elegantes sobrados ecléticos e classicistas imperiais, que, décadas mais tarde, foram substituídos por prédios de arquitetura moderna e pós-moderna - quando não apenas modernosa (e pós-modernosa?).

O MCSP é composto por doze unidades administradas pelo Departamento do Patrimônio Histórico da Prefeitura Municipal de São Paulo; reúne casas bandeiristas, museus e equipamentos culturais, dentro de uma proposta que enfatiza a interpretação do patrimônio e educação patrimonial. Mesmo o corpo discente sendo, em sua maioria, composto por paulistanos, nenhum(a) aluno(a) tinha ouvido falar dessa proposta, muito menos já tinha visitado alguma das doze unidades, com exceção do Monumento à Independência e da Casa do Grito, que ficam perto do Museu Paulista.

As unidades visitadas foram as seguintes:

a) Casa do Sítio da Ressaca: exemplar representativo não apenas das casas bandeiristas paulistas, mas também do tratamento dado a elas, nos anos 1950 e 1960, com a idealização de um passado que jamais tenha existido por completo, para lembrar Antonio Luiz Dias de Andrade (Janjão), falecido dirigente do IPHAN. Além disso, visitou-se a exposição acerca do abolicionista Luís Gama;

b) Casa Modernista, de autoria de Gregori Warchavchik, considerada a primeira edificação de estilo moderno no Brasil, e que conta com uma exposição sobre esse estilo arquitetônico, com informações sobre projetos e obras de grandes arquitetos estrangeiros;

c) Beco do Pinto, com exposições temporárias;

d) Casa da Imagem, com exposição permanente de fotografias antigas da Cidade de São Paulo;

e) Solar da Marquesa de Santos, que funciona como uma casa museu, com acervo de objetos da época na qual a Marquesa de Santos viveu na edificação, no século XIX. É a sede do MCSP. 
A visita técnica foi útil para abordar uma série de pontos interessantes junto ao corpo discente. Dado que o acervo é composto, via de regra, por edificações remanescentes do Brasil Colônia (1500-1822) e Império do Brazil (1822-1889), qual é sua representatividade para a população de uma metrópole nacional como São Paulo, cuja população cresceu e se diversificou, desde o último quartel do século XIX, a partir de grupos sociais que aparentemente nada têm a ver com esse patrimônio? Como promover e difundir esse patrimônio, quando os adjetivos histórico e artístico são comumente usados para monumentos imponentes, de arquitetura barroca, com profusão de adornos e detalhes, ou seja, longe de o que uma casa bandeirista tem a oferecer, por exemplo? Procurou-se, também, avaliar a interpretação patrimonial presente nessas unidades, através de monitores terceirizados, bem como as exposições e acervos de peças e objetos.

Cabe, aqui, uma crítica à disciplina; seu programa não contemplou textos de interpretação patrimonial, a exemplo de Murta e Albano (2002), que tornariam a visita técnica mais proveitosa ao corpo discente.

A disciplina contemplou uma viagem técnica, com duração de três dias, à Cidade de Iguape, no litoral sul do Estado de São Paulo, cujo centro histórico foi tombado pelo IPHAN, em 2009. Desde sua concepção inicial, o principal objetivo da viagem técnica era aplicar o conteúdo dado em sala de aula e presente na bibliografia de Políticas de Cultura; além disso, possibilitou-se que os(as) discentes travassem contato com três equipamentos culturais existentes em Iguape. O mais importante é a Casa do Patrimônio de Iguape, centro patrimonial do IPHAN, que tem como objetivos, da mesma forma que outras casas de patrimônio, promover e difundir o patrimônio cultural da cidade e região - no caso, o Vale do Ribeira -, e servir de ponto de contato permanente com a comunidade local. Trata-se de uma proposta inovadora, que conjuga as funções de pesquisa, difusão e educação patrimonial em um só espaço. Apesar de muito pequena, quando comparada com outras unidades desse tipo do IPHAN - por exemplo, a do Recife, instalada no imponente Palácio da Soledade -, a Casa do Patrimônio de Iguape cumpre bem sua função, contando com bom acervo bibliográfico, cartazes sobre algumas cidades do Vale do Ribeira e equipe técnica solicita.

Contemplou-se também o Museu Histórico e Arqueológico de Iguape, que segue uma linha mais "tradicional," com seu acervo de peças que contam a história do município e região. Apesar de Iguape possuir uma trajetória histórica e patrimônio cultural relevantes, nota-se, como ocorre em outras cidades patrimoniais, a pobreza de seu museu histórico e arqueológico. Como aponta Durand (1989), a valorização do colonial, a partir dos anos 1920, transferiu para coleções e acervos nacionais e internacionais grande parte dos bens móveis dessas cidades; provavelmente, isso não deixou de acontecer em Iguape, inclusive pelo longo processo de decadência econômica municipal, acentuado nos últimos trinta anos. Soma-se a isso a falta de uma política de aquisição 
permanente de objetos e acervos, fato (infelizmente) comum nas instituições culturais brasileiras.

Por fim, visitou-se a Oficina Cultural Regional Gerson de Abreu, instalada na antiga Casa de Câmara e Cadeia de Iguape, imóvel do século XIX. Aproveitou-se para discutir a utilização de uma edificação redundante - incapaz de sustentar o uso para a qual foi projetada - para atividades de fomento e criação cultural. Aproveitando-se da presença de dois funcionários responsáveis pela programação cultural do equipamento, foi possível discutir o funcionamento das oficinas culturais no Estado de São Paulo, bem como o caso particular do Vale do Ribeira.

Nos três equipamentos culturais, foi possível dialogar com dirigentes culturais e funcionários.

A viagem técnica contemplou a visita ao conjunto arquitetônico e paisagístico de Iguape, com destaque para seus principais monumentos, à Il ha Comprida, com destaque para o ponto de concentração de bares e restaurantes na praia, junto com o centro comercial da cidade, e a alguns pontos nos arredores da área central de Iguape, importantes para se compreender a história local ou ter vistas sobre o sítio tombado.

\section{Considerações finais}

O balanço final da oferta da disciplina Políticas de Cultura (ACH3598), no primeiro semestre de 2012, aponta três oportunidades e pontos positivos; contudo, cabe destacar, desde já, seus limites e pontos negativos, considerando-se seus objetivos junto ao corpo discente de GPP e LZT. Cumpre, como fecho desse trabalho, destacá-los um por um, para que o(a) leitor(a) tenha condições de refletir sobre essa experiência particular de ensino.

O primeiro ponto positivo de destaque é a mescla, em sala de aula, atividades extraclasse e trabalhos semestrais, de alunos(as) de GPP e LZT. Por mais que a EACH conte com o Ciclo Básico, conjunto de disciplinas que o corpo discente de seus dez cursos de graduação precisa cumprir, no primeiro ano, nota-se que, depois disso, cada curso desenvolve-se de forma estanque em relação aos outros, o que limita a proposta multidisciplinar e interdisciplinar da unidade.

Destaca-se também a descoberta de uma área até então ignorada no campo da gestão governamental e políticas públicas, por parte dos(as) discentes de GPP. O importante, nesse caso, não é convencer os(as) alunos de que a área patrimonial é importante. Trata-se de algo mais básico: dar a oportunidade para que eles(as) conheçam-na, e, a partir disso, possam decidir se ela é importante ou não. Pela falta de informação e baixa importância da questão dos bens culturais no supracitado campo, não se permite que acadêmicos, pesquisadores e 
profissionais sequer avaliem a intervenção pública na área patrimonial, devido à absoluta falta de informações e conhecimento.

Outro ponto importante é a reflexão acerca do nacional para alem do pragmático, abordando-se o lado formativo e simbólico do termo - cultura, patrimônio, identidade e memória. A reflexão acerca de o que se constitui nacional, e qual é sua importância para o povo brasileiro, não é algo que faça parte das preocupações e imaginário do corpo discente de GPP e LZT, dada a experiência de ensino nesses dois cursos da EACH. Inclusive, essa reflexão motivou alguns(mas) discentes a ler textos da bibliografia complementar da disciplina, ou, então, a se interessar pela história e formação de grupos sociais particulares importantes para a formação e trajetória do povo brasileiro, como os afrodescendentes.

Contudo, a disciplina apresentou alguns limites e pontos negativos, que não podem ser ignorados, inclusive pensando em sua oferta futura. Primeiro, a atuação profissional na área patrimonial não é avaliada como promissora e atrativa, por parte dos(as) alunos(as); infelizmente, isso atingiu a quase unanimidade, mesmo pelos que avaliam importante a intervenção pública nela. Há três problemas aqui, na visão do corpo discente, a saber: a) a precariedade das políticas patrimoniais, com a predominância de ações e projetos desconexos; b) as poucas oportunidades profissionais para egressos de GPP e LZT, principalmente pela dominância dos arquitetos e urbanistas nessas políticas; e c) a avaliação de outras áreas culturais como mais dinâmicas e atrativas, principalmente as ligadas à criação e fomento cultural.

Houve também a falta de contato com dirigentes e funcionários públicos com atuação na área patrimonial, nas três esferas de governo, com exceção da viagem técnica à cidade de Iguape. Nesse caso, houve a oportunidade de conversar com dirigentes e funcionários na Casa do Patrimônio de Iguape (federal), Oficina Cultural Regional Gerson de Abreu (estadual) e Museu Histórico e Arqueológico de Iguape (municipal), além do titular do Departamento de Cultura, Turismo, Esportes e Eventos da prefeitura municipal. Contudo, faltou à disciplina a palestra ou aula de um gestor público com larga experiência, que pudesse passar aos discentes uma visão geral, bem como os principais avanços e problemas da área patrimonial.

Outro problema percebido é que parte do corpo discente cursou a disciplina como se o estudo das políticas patrimoniais não merecesse a mesma dedicação que matérias consideradas mais sérias, como economia ou estatística. Isso se mostrou evidente, desde o início do curso, através de uma intensa participação em sala de aula, mas com a falta quase que absoluta de leitura, por parte considerável dos(as) alunos(as) matriculados(as). O principal resultado disso foi a discussão de muitas questões a partir de argumentos e pontos de vista centrados no relativismo cultural, tão em voga nesses tempos pós-modernos, que se repetiram aula após aula, mas acompanhada pela falta de repertório acerca dos 
temas e assuntos em discussão, pela ausência de leitura, o que a tornou, com o passar das aulas, pobre e baseada em frases prontas e clichês.

Outro resultado dessa falta de dedicação foi a alta reprovação da disciplina, em virtude da desistência pura e simples de muitos(as) discentes, no final do semestre. Confrontados(as) com dois trabalhos semestrais de fôlego, alguns(mas) discentes simplesmente abandonaram o curso, pois seus objetivos já tinham sido cumpridos, a saber: travar contato com a área patrimonial, e conhecer os bens culturais mais importantes do país. Dado que muitos(as) alunos(as) de GPP matriculam-se em mais créditos do que precisam para se formar, a desistência de passar em Políticas de cultura não afetou os planos de formatura de muitos(as) deles(as).

Por fim, sem desmerecer a cidade de Iguape, a disciplina se beneficiaria mais escolhendo outra cidade patrimonial para sua visita técnica. Isso se deve ao fato de Iguape não enfrentar uma série de problemas comuns a várias cidades patrimoniais, no Brasil e no mundo, que são desafiadores à gestão pública. Iguape não enfrenta problemas de especulação imobiliária, nem é um destino turístico importante, tampouco seu tombamento pelo IPHAN enfrenta resistência das autoridades locais ou conjunto da população, de forma geral. A cidade também não é alvo do Programa Monumenta, nem tem um histórico de intervenções públicas relevantes sobre seu patrimônio cultural. Coube ao docente responsável essa escolha; reforça-se que não há, aqui, nenhum demérito a Iguape, cujo conjunto arquitetônico e urbanístico tombado é importante ao patrimônio cultural brasileiro, mas a disciplina seria mais bem contemplada com uma viagem técnica a Ouro Preto ou Paraty, por exemplo, que enfrentam problemas desse tipo.

\section{Referências}

Bennett O. Cultural policy in the United Kingdom: Collapsing rationales and the end of a tradition. Cultural policy 1995, 1(2):199-216.

Botelho I. Dimensões da cultura e políticas públicas. São Paulo em Perspectiva. 2001, 15(2):73-83.

Brasil. Constituição da República dos Estados Unidos do Brasil, de 16 de julho de 1934. Rio de Janeiro, 1934.

Brasil. Constituição da República Federativa do Brasil, de 05 de outubro de 1988. Brasília, 1988.

Brasil. Decreto 3.551, de 04 de agosto de 2000. Brasília, 2000.

Brasil. Decreto-lei 25, de 30 de novembro de 1937. Rio de Janeiro, 1937. 
Brasil. Ministério da Cultura. Instituto do Patrimônio Histórico e Artístico Nacional. Relatório de gestão 2011. Brasília: IPHAN, 2012.

Brasil. Secretaria de Planejamento da Presidência da República. Ministério da Educação e Cultura. Programa Integrado de Reconstrução das Cidades Históricas do Nordeste: Exposição de motivos n. 076-B. Brasília: SEPLAN/PR / MEC, 1973.

Choay F. A alegoria do patrimônio. 3ạ edição. São Paulo: Estação Liberdade / UNESP, 2006.

Costa L. Prefácio. In: Andrade RMF. Rodrigo e seus tempos. Rio de Janeiro: Fundação Nacional Pró-Memória, 1986.

Cury | (Coord.). Cartas patrimoniais. 3ạ edição revista e aumentada. Rio de Janeiro: IPHAN, 2004.

Durand JC. Arte, privilégio e distinção: Artes plásticas, arquitetura e classe dirigente no Brasil, 1855/1985. São Paulo: Editora Perspectiva / Editora da Universidade de São Paulo, 1989.

Falcão J. A política cultural de Aloísio Magalhães. In: Magalhães A. E Triunfo? A questão dos bens culturais no Brasil. Rio de Janeiro: Nova Fronteira; Fundação Roberto Marinho, 1997.

Fonseca MCL. O patrimônio em processo: trajetória da política federal de preservação no Brasil. 2a edição revista e ampliada. Rio de Janeiro: Editora UFRJ / MinC - IPHAN, 2005.

Gastal S. Projeto Monumenta: Filosofia e práticas em interface com o turismo. Turismo em análise 2003, 14(2):77-89.

Graduação em Gestão de Políticas Públicas (GPP). Projeto político pedagógico (PPP). São Paulo: GPP, 2012.

Harvey D. Condição pós-moderna: Uma pesquisa sobre as origens da mudança cultural. São Paulo: Edições Loyola, 2005.

Instituto do Patrimônio Histórico e Artístico Nacional (IPHAN). Anais do // Encontro de Governadores para preservação do patrimônio histórico, artístico, arqueológico e natural do Brasil. Rio de Janeiro: IPHAN, 1973.

Köhler AF, Durand JCG. Turismo cultural: Conceituação, fontes de crescimento e tendências. Revista Turismo - Visão e Ação 2007, 9(2):185-198.

Köhler AF. Patrimônio cultural, turismo e gestão pública: Exploração turística predatória e desvalorização patrimonial em Igarassu, Brasil. PASOS. Revista de Turismo y Patrimonio Cultura/2011, 9(2):265-278. 
Machado MB. Notas sobre política cultural no Brasil. In: Miceli S (Org.). Estado e cultura no Brasil. São Paulo: Difel, 1984.

Magalhães A. E Triunfo? A questão dos bens culturais no Brasil. Rio de Janeiro: Nova Fronteira ? Fundação Roberto Marinho, 1997.

Meethan K. Consuming (in) the civilized city. Annals of tourism research 1996 , 23(2):322-340.

Miceli S. O processo de "construção institucional" na área cultural federal (anos 70). In: Miceli S (Org.). Estado e cultura no Brasil. São Paulo: Difel, 1984.

Murta SM, Albano C (Orgs). Interpretar o patrimônio: Um exercício do olhar. Belo Horizonte: UFMG / Território Brasilis, 2002.

Ortiz R. Cultura brasileira e identidade nacional. 5a edição. São Paulo: Brasiliense, 2006.

Souza C. Políticas públicas: Uma revisão da literatura. Sociologias 2006, 8(16):2045.

Szmrecsányi MI. A soCleDADE brasileira: Entre a modernidade e a pósmodernidade. In: Szmrecsányi MI (Org.). Da soCleDADE moderna à pósmoderna no Brasil: Permanências e mudanças urbanas, séculos XX e XXI. São Paulo: Annablume / FAPESP, 2011.

Taddei P. Os grandes projetos. In: Weffort F; Souza M (Orgs.). Um olhar sobre a cultura brasileira. Rio de Janeiro: Associação de Amigos da FUNARTE, 1998.

Toledo BL. São Paulo, três cidades em um século. 4ạ edição. São Paulo: Cosac \& Naify, 2007.

Volkerling M. Deconstructing the difference-engine: A theory of cultural policy. Cultural policy 1996, 2(2):189-212.

Weffort F. O nacionalismo, o populismo e o que restou do legado político e econômico de Vargas. In: Szmrecsányi T; Granziera RG (Orgs.). Getúlio Vargas e a economia contemporânea. Campinas: Editora da UNICAMP / Editora Hucitec, 2004. 